\title{
The emperor's old clothes
}

Timothy Ferris

From Eros to Gaia. By Freeman Dyson. Pantheon: 1992. Pp. 371. \$25.

MANY eminent scientists, having attained acclaim through their research in physics, mathematics or some other specialized discipline, become eager to write on matters far beyond their fields of expertise. The resulting books and essays, obedient though they may be to Schopenhauer's encouraging dictum that "the first forty years of life give us the text [while] the next thirty supply the commentary", are not uniformly praiseworthy. Indeed, to be blunt, the popular science literature is littered with windy, ill-thought-out tomes written by scientific celebrities who honour publishing contracts by hastily committing their loosely anchored opinions to the printed page. Particularly notable are 'follow-up' books - collections of speeches, old essays and juvenilia siphoned from the files of scientists whose earlier haute vulgarisations did well enough for their publishers to urge them to get another volume out pronto.

Freeman Dyson is an eminent physicist whose popular books (Infinite in All Directions, Disturbing the Universe, Weapons and Hope) are widely read on both sides of the Atlantic. From Eros to Gaia, his latest offering, scrapes so deeply into his filing cabinets that the merest perusal of its table of contents is apt to awaken a sense of alarm among students of the genre. It begins with the unfinished manuscript of a science fiction tale, "Sir Phillip Robert's Erolunar Collision", written by Dyson in 1933, when he was nine years old. Most of the rest of its 35 chapters are based on speeches Dyson gave and book reviews and essays he contributed to The New Yorker, The Mathematical Intelligencer, Scientific American, American Journal of Physics and other publications.

Yet to read this book is to dispel one's trepidations. Dyson turns out to be a happy exception to the baleful rule.

Born in England and a resident of the United States since 1951, Dyson has contributed significantly to the literature of theoretical physics. (He is, for instance, one of the four authors of the theory of quantum electrodynamics, and is said to have been excluded from winning the 1965 Nobel prize in physics only because the prize is limited to three recipients.) $\mathrm{He}$ is also a man of wide interests, ranging from interstellar spaceflight to technology policy, global ecology and science education. His writing on these subjects is clear, incisive and free from rhetorical excess.
I can think of no comparable author whose work is more selfless and genuinely helpful. From Eros to Gaia may be a collection of old stuff, but it adds up to an exceptionally rewarding read.

Emblematic of Dyson's poise and independence of thought are his essays here on the issue of how much money governments should spend on 'big science' endeavours such as the Hubble Space Telescope rather than more modest projects such as the International Ultraviolet Explorer. The Hubble Telescope cost a billion dollars. Its myopic main mirror made it an instant and embarrassing failure. The International Ultraviolet Explorer was launched in 1978 , by a Delta rocket, on a shoestring budget. It has been pouring out data on young stars, supernovae, quasars and other celestial wonders ever since, sparking, Dyson notes, "more than a thousand papers in professional astronomical journals."

The lesson Dyson draws from all this is not the predictable one that big science is bad and small science good. In- stead, he urges that attention be paid to the question of whether a big project can be accommodated within the "ecology" of the field to which it belongs. In particular, he sagely comments, planners should try to leave room for the waste and inefficiency required if scientists and engineers are to find out what works and what does not:

The right size means a size at which you can afford to take a gamble.... If you are too big to gamble, you are too big to do creative science... The moral is not 'small is bcautiful' [but] 'different is beautiful'.

Always one of our most visionary speculators about the far future, Dyson muses imaginatively about the long-term potential of spaceflight:

Spacecraft should weigh pounds rather than tons, they should cost tens of thousands rather than tens of millions of dollars, and they should fly missions at a rate of several per day rather than several per year.

He foresees an unmanned space probe for the year 2018:

I call this model the Astrochicken because it is about as big as a chicken and about as smart. It is a product of genetic engineering. It does not look like a chicken. It looks more like a butterfly. It has wide and thin solar sails instead of wings, and a high-resolution spectroscopic imaging sys-

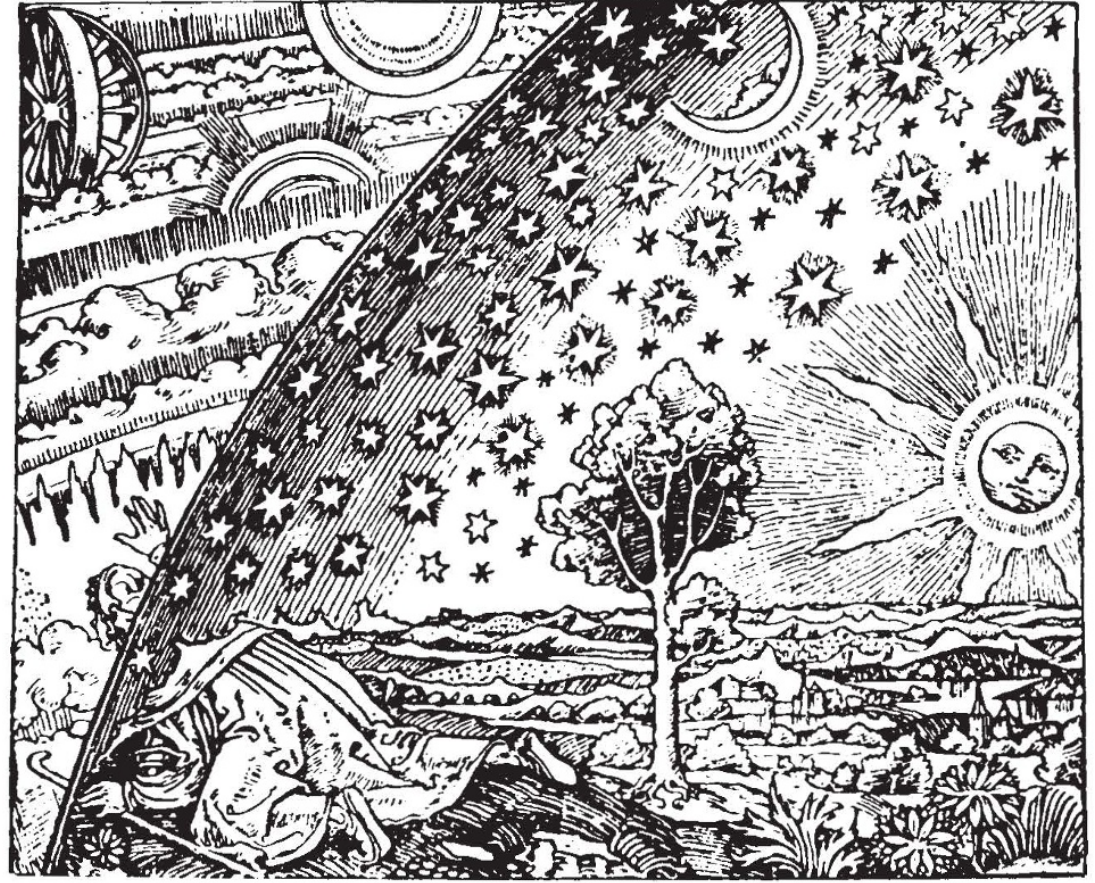

Machinery of the heavens - a scholar, identifled by his cap and gown, pierces the shell of the stars to observe the great wheels that move the heavenly bodies. The woodcut illustrates the mechanistic explanation of the cosmology proposed by the German cardinal Nicholas de Cusa (1401-1464). This picture is one of over a hundred reproduced in Harry Robin's The Scientific Image: From Caveman to Computer. Abrams, $\$ 39.95$. 